\title{
Single-dose baclofen-induced neurotoxicity in a patient with end stage renal disease: case report
}

\author{
Emad Khazneh ${ }^{1}$, Alaa Shamlawi ${ }^{2}$, Kamel Jebrin ${ }^{1}$, Zakaria Hamdan ${ }^{1}$ and Osama Sawalmeh ${ }^{3^{*}}$
}

\begin{abstract}
Background: Baclofen is a centrally acting $G A B A_{B}$ receptor agonist and it is used widely for the treatment of spasticity, persistent hiccups and multiple sclerosis. The renal system is the main route of excretion, thus people with suboptimal renal function are prone to baclofen intoxication. Multiple doses of baclofen have been associated with toxicity, but it is very unusual that single dose can do so.

Case presentation: A 47 year old female patient with end stage renal disease (ESRD) presented with a sudden onset of altered mental status and state of unconsciousness after the ingestion of one tablet of baclofen $25 \mathrm{mg}$. All other possible causes were ruled out and a diagnosis of baclofen toxicity was considered. The patient showed dramatic improvement after an extra two sessions of hemodialysis.

Conclusions: We highly recommend that more educational efforts are made for health care professionals about the possible risk of baclofen toxicity among kidney-impaired patients. We also recommend avoiding baclofen use if evidence of chronic renal disease is present and to seek other alternatives for pain management.
\end{abstract}

Keywords: Baclofen, Toxicity, Neurotoxicity, End stage renal disease, ESRD, Chronic kidney disease, Overdose, Case report

\section{Background}

Baclofen, $\beta$-4-chlorophenyl gamma-aminobutyric acid, is a natural derivative of the neurotransmitter gamma-aminobutyric acid (GABA) [1, 2]. Specifically, it is considered as an active agonist for $\mathrm{GABA}_{B}$ receptors [2]. Baclofen acts centrally, thus it has been used to treat skeletal muscle spasms, persistent hiccups, multiple sclerosis and other spinal cord lesion-induced spasticity $[1,3,4,5]$. Baclofen is absorbed primarily by the gastrointestinal tract and more than $80 \%$ is excreted by the kidneys [6]. This explains why people with reduced kidney function are at higher risk of intoxication than those with normal kidney function. The half-life of Baclofen ranges between 4.5-6.8 $\mathrm{h}$. This half-life increases in patients with impaired renal function [7]. Baclofen can cross the Blood-Brain barrier only very slowly for central nervous system penetration but if the half-life is extended this leads to more CNS

\footnotetext{
* Correspondence: osamah.2008@yahoo.com

${ }^{3}$ Intern Doctor, Internal Medicine Department, An-Najah National University

Hospital, Nablus, Palestine

Full list of author information is available at the end of the article
}

penetration and its effect in term of CNS depression can be easily pronounced $[3,6]$.

This case report presents a patient with end-stage renal disease suffering from single-dose induced Baclofen toxicity. She presented with altered mental status and improved dramatically after high-efficiency intensive hemodialysis sessions.

\section{Case presentation}

A 47-year-old female patient presented to the dialysis unit with decreased level of consciousness and sleepiness of two days duration. Her past medical history is end stage renal disease and regular hemodialysis 3 times/week for 2.5 years, controlled hypertension. She is non-diabetic. Her past surgical history included arteriovenous fistula before 2.5 years, appendectomy and tonsillectomy long time ago.

The patient was in her usual state of health of moderate exercise tolerance until two days before admission when she started to experience lower back and bilateral knee pain that was vague in nature and associated with insomnia. That time, she received one tablet of baclofen 
$25 \mathrm{mg}$ from her sister. Her sister used to ingest baclofen for chronic neck pain. The patient fell into a deep sleep throughout that night and entire next day without any wakefulness periods. Two days later, she went to her usual hemodialysis session and there the medical personnel noticed her high blood pressure and a state of unconsciousness for which she was sent back to the emergency department after the hemodialysis session. The family denied any previous similar episodes or limb weakness, numbness, dysarthria, dysphagia or mouth deviation before the event. There is no history of fever, photophobia, neck stiffness, falling down or any psychosocial problems. She had not travelled or had any contact with sick people. She was compliant to her hemodialysis sessions. She is a 20 pack-year smoker but does not use any illegal drugs or consume alcoholic drinks. Her home medications were: Atenolol $50 \mathrm{mg} /$ day, Amlodipine $5 \mathrm{mg} /$ day, $\mathrm{CaCO}_{3} 600 \mathrm{mg} /$ day and alfacalcidol $0.25 \mathrm{ugm} /$ day.

On examination, the vital signs were as follows: Temperature: $36.4{ }^{\circ} \mathrm{C}$, Blood pressure: $220 / 110$, pulse: 95 beat/minute, respiratory rate: $14 / \mathrm{min}$, oxygen saturation: $95 \%$ on room air. On admission, the Glasgow Coma Scale was $9 / 15$. She was unconscious. Deep tendon reflexes were absent. There was no obvious facial asymmetry, left pupil was round and reactive to light (right eye is artificial due to previous trauma). Gag reflex was intact but the cranial nerves could not be assessed. The fundus was examined and no papilledema or hemorrhage were seen. The breathing sounds were heard bilaterally on the chest with no added sounds. Abdominal examination was unremarkable.

Lab results at admission were: Hemoglobin: $16.1 \mathrm{~g} / \mathrm{dL}$, White blood cells: $6.8 \mathrm{~K} / \mathrm{ul}$, platelets: $155 \mathrm{~K} / \mathrm{ul}$, Sodium: $138 \mathrm{mEq} / \mathrm{L}$, potassium: $4.4 \mathrm{mEq} / \mathrm{L}$, chloride: $95 \mathrm{mEq} / \mathrm{L}$, CRP: $1.6 \mathrm{mg} / \mathrm{L}$, Glucose: $99 \mathrm{mg} / \mathrm{dL}$, ABG's: $\mathrm{pH}: 7.44$, $\mathrm{pCO}_{2}: 36.6 \mathrm{mmHg}, \mathrm{pO}_{2}: 88 \mathrm{mmHg}, \mathrm{HCO}_{3}: 24.4 \mathrm{mEq} / \mathrm{L}$, albumin: $4.4 \mathrm{~g} / \mathrm{dL}$, alkaline phosphatase: 88 , total bilirubin: $0.5 \mathrm{mg} / \mathrm{dL}$, direct bilirubin: $0.2 \mathrm{mg} / \mathrm{dL}, \mathrm{BUN}: 27 \mathrm{mg} /$ $\mathrm{dL}$, Creatinine: $5.5 \mathrm{mg} / \mathrm{dL}$. Liver function tests were within normal ranges. To rule out any brain ischemia or hemorrhage, brain computed topography (CT scan) was done on the day of admission and Magnetic resonance imaging (MRI) of the brain was done on the second day of admission. CT scan showed no significant lesions, no hemorrhage or any other defects. MRI showed no signs of recent ischemic stroke, intracranial hemorrhage, space-occupying lesion or midline shift. The hypertension was controlled by labetalol IV infusion pump.

After ruling out all possible causes of her decreased level of consciousness, including Posterior reversible encephalopathy syndrome (PRES), baclofen toxicity was considered as the cause. She was started on flumazenil $0.25 \mathrm{mg}$ and on intensive daily ultrafiltration hemodialysis sessions since the first day of admission with total of three extra hemodialysis sessions. The improvement started to be noticed at the second day when she was semi-conscious, hallucinating, obeying commands as ordered but still not oriented to time, place or person. GCS was 10/15. The dramatic improvement was on the next day after a total of two extra hemodialysis sessions, she was fully awake, GCS $15 / 15$, able to obey commands but still not well oriented so a third extra session was considered. After three days of admission and a total of five hemodialysis sessions, she was discharged after she had returned to her previous baseline state of health and she was instructed not to receive baclofen again.

\section{Discussion}

Baclofen is a natural derivative agonist of $\mathrm{GABA}_{\mathrm{B}}$ receptors at the level of the spinal cord thus producing its attenuating effect on the muscle tone if used within the therapeutic range [1]. The daily therapeutic dose ranges between 5 and $60 \mathrm{mg}[7,8]$. Adverse effects with baclofen overdose have been noticed among people with normal kidney function such as sedation, confusion, muscle weakness and impaired consciousness [1] and these effects are attributed to its inhibitory effect on the central nervous system [6]. The reported doses of intoxication were between $80 \mathrm{mg}$ and $2500 \mathrm{mg}$ with the more severe among those who have ingested more than $200 \mathrm{mg}$ requiring more intensive care unit admissions and for longer durations [9].

The situation becomes more complicated in those with impaired renal function as baclofen is mainly excreted by the renal system $(85-90 \%)$ and the rest, $10-15 \%$, becomes metabolized by the liver [6]. Based on this data, and knowing that the liver function is intact, or, at least, not impaired, as the liver enzymes and other related laboratory variables were within the normal range, the impaired kidney functioning capacity is the only one to be blamed as the cause of baclofen toxicity. The reported doses of baclofen toxicity among patients with chronic kidney disease ranges between $5 \mathrm{mg}$ and 60 mg per day, and most of the patients were known to have advanced kidney disease [10]. The onset of symptoms usually started 2-3 days after the ingestion of baclofen $[4,10]$ but as early as $24 \mathrm{~h}$ have also been documented among those with end-stage renal disease [6]. However, our case developed a state of sleepiness and unconsciousness as soon as $12 \mathrm{~h}$ post ingestion of a single dose of $25 \mathrm{mg}$. The impaired excretion is responsible for the toxic effects of baclofen even with normal therapeutic doses as it accumulates and induces neurotoxicity [4].

Among the presumed differentials is PRES, posterior reversible encephalopathy syndrome. PRES is a group of neurological signs and symptoms and characteristic 
radiologic findings that are usually reversible [11]. Clinically, PRES is diagnosed by acute onset of headache, seizures, visual problems and encephalopathy' in addition to the radiologic findings of vasogenic edema, either by CT or MRI (Preferred), mainly affecting the parieto-occipital lobes [12]. Referring to our patient, PRES could easily be excluded as, by definition, PRES should have radiologic findings as part of the diagnostic criteria and both CT and MRI were done for the patient and no one could identify any consistent findings for PRES or any other intracranial lesion that might explain the clinical picture of the patient.

The manifestations of baclofen toxicity are dizziness, nausea, vomiting, respiratory depression, altered mental status, ataxia, dystonia and coma [3, 6, 8, 13]. Reversible akinetic mutism [14] and severe comatose state with absent brain stem reflexes have been documented with severe baclofen intoxication [15]. The degree of chronic renal failure varied among patients from acute kidney injury to stage 5 chronic renal failure and eventually end stage renal disease $[6,15]$.

The mainstay of treatment is supportive and close monitoring for possible respiratory compromise [6]. Hemodialysis is also a very reliable method of treatment as it decreases baclofen half-life in ESRD patients from 15 to $2 \mathrm{~h}$ [16]. Some reported cases improved dramatically after only one session as it is thought to eliminate baclofen from the body as do normal kidneys [16-18] but other patients needed up to five sessions for complete recovery [6]. Our patient started to show improvement after two hemodialysis sessions and the complete recovery was gained after a total of five. Continuous Renal Replacement Therapy seems to be a good substitution for those patients who are not a candidate for hemodialysis [6].

In the published literature, there is still a much debate of what dose of baclofen to use in patients with impaired kidney function and when to start decreasing or discontinuing the dose $[4,7,15]$. Roberts et al. [6] provided a clear suggestion of totally avoiding baclofen use among ESRD and acute renal failure patients and those with a glomerular filtration rate less than $60 \mathrm{ml} /$ minute. They also suggested to use the lowest possible dose for those with mild chronic kidney disease, GFR more than $60 \mathrm{ml} /$ minute [6].

Another presumed hypothesis to explain what happened to the patient is the finding of significantly elevated blood pressure at the time of diagnosis and whether or not it might have contributed to the increased risk of baclofen toxicity, even with a single dose as noticed in our case. Up to the authors' knowledge, not one study was reported to prove or disprove this hypothesis as most of the reported cases had normal or slightly elevated blood pressures [1, 3, 4, 8, 15].

\section{Conclusions}

In conclusion, Baclofen toxicity is a serious, life threatening condition, especially for those with impaired renal function. Patients with suboptimal renal function presenting with altered mental status with a history of baclofen ingestion should prompt the diagnosis of baclofen toxicity. As soon as the diagnosis is made and hemodialysis is initiated, it can be completely reversible without any sequelae. More efforts should be done towards educating health care professionals about the possible risks of baclofen use with ESRD patients. We also recommend avoiding baclofen use among patients with decreased renal function, even if mild chronic renal failure, as the accumulation in the CNS is cumulative and depends on the renal excretion capacity. Therefore, we highly recommend seeking other alternatives.

\section{Abbreviations}

$\mathrm{CaCO}_{3}$ : calcium bicarbonate; CNS: central nervous system; $C \mathrm{~T}$ : computed topography; ESRD: end stage renal disease; GABA: gamma-aminobutyric acid; GCS: Glasgow coma scale; MRI: magnetic resonance imaging

\section{Acknowledgments}

We thank the internal medicine resident doctors and nursing staff in the internal medicine department and hemodialysis unit at An-Najah National University Hospital for making the study possible. Special thanks go to Ms. Eman Abusalameh and Dr. Mujahed Shraim for their valuable linguistic comments.

Funding

No funding was received for conducting the study.

\section{Availability of data and materials}

Data are all contained within the case report. The raw data are available by the corresponding author when requested.

\section{Authors' contributions}

EK, OS, AS, KJ and ZH designed the study and its protocol. OS and AS collected the data. All authors managed follow-up of the patient. All authors reviewed the manuscript critically for important intellectual content. All authors read and approved the final manuscript for submission.

Ethics approval and consent to participate

Full verbal and written consent has been obtained from patient herself.

Consent for publication

Written consent was obtained from the patient for publication of this Case report and. A copy of the written consent is available for review by the Editor of this journal.

Competing interests

The authors declare that they have no competing interests.

\section{Publisher's Note}

Springer Nature remains neutral with regard to jurisdictional claims in published maps and institutional affiliations.

\section{Author details}

${ }^{1}$ Nephrology Consultant, Nephrology department, An-Najah National University Hospital, Nablus, Palestine. ${ }^{2}$ Internal Medicine resident, Internal Medicine Department, An-Najah National University Hospital, Nablus, Palestine. ${ }^{3}$ Intern Doctor, Internal Medicine Department, An-Najah National University Hospital, Nablus, Palestine. 
Received: 16 March 2018 Accepted: 30 November 2018

Published online: 11 December 2018

\section{References}

1. Ghose K, Holmes KM, Matthewson K. Complications of baclofen overdosage. Postgrad Med J. 1980;56(662):865-7.

2. Reis GM, Duarte ID. Baclofen, an agonist at peripheral GABAB receptors, induces antinociception via activation of TEA-sensitive potassium channels. Br J Pharmacol 2006; 149:733-739. [PubMed: 17016510].

3. Meillier, Andrew, Cara Heller, and Shyam Patel. "Baclofen-induced encephalopathy in end stage renal disease." Case Rep Med 2015 (2015): 203936. PMC. Web. 18 Sept. 2018

4. Radhakrishnan H. Baclofen-induced neurotoxicity in a patient with endstage renal disease. Saudi Journal of Kidney Diseases and Transplantation. 2016;27(3):595

6. Roberts JK, Westphal S, Sparks MA. latrogenic baclofen neurotoxicity in ESRD: recognition and management. Seminars in dialysis. 2015;28(5):525-9.

5. Zhang C, Zhang R, Zhang S, Xu M, Zhang S. Baclofen for stroke patients with persistent hiccups: a randomized, double-blind, placebo-controlled trial. Trials. 2014;15(1):295.

7. Bassilios N, Launay-Vacher V, Mercadal L, Deray G. Baclofen unerotoxicity in a chronic haemodialysis patient. Nephrology Dialysis Transplantation. 2000; 15(5):715-6.

8. Ijaz M, Tariq H, Kashif M, Marquez JG. Encephalopathy and Hypotonia due to baclofen toxicity in a patient with end-stage renal disease. The American journal of case reports. 2015:16:232.

9. Leung NY, Whyte IM, Isbister GK. Baclofen overdose: defining the spectrum of toxicity. Emergency Medicine Australasia. 2006;18(1):77-82.

10. El-Husseini A, Sabucedo A, Lamarche J, Courville C, Peguero A. Baclofen toxicity in patients with advanced nephropathy: proposal for new labeling Am J Nephrol. 2011;34(6):491-5.

11. Fischer M, Schmutzhard E. Posterior reversible encephalopathy syndrome. J Neurol. 2017;264(8):1608-16.

12. Fugate JE, Claassen DO, Cloft HJ, Kallmes DF, Kozak OS, Rabinstein AA Posterior reversible encephalopathy syndrome: associated clinical and radiologic findings. In Mayo Clin Proc. 2010;Vol. 85(5):427-32 Elsevier.

13. Porter LM, Merrick SS, Katz KD. Baclofen toxicity in a patient with hemodialysis-dependent end-stage renal disease. The Journal of emergency medicine. 2017:52(4):e99-e100.

14. Rubin DI, So EL. Reversible akinetic mutism possibly induced by baclofen. Pharmacotherapy: The Journal of Human Pharmacology and Drug Therapy. 1999;19(4):468-70.

15. Mousavi SB, Mousavi MB, Motemednia F. Baclofen-induced encephalopathy in patient with end stage renal disease: two case reports. Indian journal of nephrology. 2012;22(3):210.

16. Wu VC, Lin SL, Lin SM, Fang CC. Treatment of baclofen overdose by haemodialysis: a pharmacokinetic study. Nephrology Dialysis Transplantation. 2005:20(2):441-3.

17. Brvar M, Vrtovec M, Kovač D, Kozelj G, Pezdir T, Bunc M. Haemodialysis clearance of baclofen. Eur J Clin Pharmacol. 2007:63(12):1143-6.

18. Justo-Ávila P, Fernández-Antuña L, Compte-Jove MT, Gállego-Gil C. Baclofen neurotoxicity in a patient with end-stage chronic renal failure. Nefrología. 2014;34(4).

Ready to submit your research? Choose BMC and benefit from:

- fast, convenient online submission

- thorough peer review by experienced researchers in your field

- rapid publication on acceptance

- support for research data, including large and complex data types

- gold Open Access which fosters wider collaboration and increased citations

- maximum visibility for your research: over $100 \mathrm{M}$ website views per year

At $\mathrm{BMC}$, research is always in progress.

Learn more biomedcentral.com/submissions 